\title{
MOVIMENTOS SOCIAIS COMO ACONTECIMENTOS: LINGUAGEM E ESPAÇO PÚBLICO
}

\author{
Ricardo Fabrino Mendonça*
}

"O início não é simplesmente uma metade do todo; ele se prolonga até o final."

PolíBio

Indagações sobre o surgimento e a manifestação de ações coletivas são recorrentes nas ciências humanas. Pesquisadores de diversas áreas debruçam-se sobre um amplo leque de fenômenos - que vão desde os chamados processos de massificação até as lutas emancipatórias, passando por aglomerações episódicas casuais - para entender aquilo que agrega indivíduos e os procedimentos que orquestram formas coletivas de comportamento. Nesse sentido, as teorias que se voltam para a compreensão de movimentos sociais mostram-se um campo especialmente rico, fazendo dialogar conceitos e iluminando uma multiplicidade de questões.

Desde os primeiros apontamentos sobre o comportamento coletivo, presentes nas obras de Le Bon, Tarde, Marx ou Freud, observa-se uma profusão de interpretações bastante divergentes sobre o caráter dos movimentos sociais e de suas ações ${ }^{1}$. Das hipóteses psicológicas observadas nos

\footnotetext{
* Agradeço os comentários de César Guimarães, Rousiley Maia, Ângela Marques e Paula Simões na elaboração deste artigo.

${ }^{1}$ Para análises sobre teorias de movimentos sociais, ver Alexander (1998), Prado (2001), Gohn (2002) e Mueller (1992).
} 
EUA do início do século XX às vertentes culturalistas que marcaram o final do mesmo século, há uma longa e multifacetada trajetória, valendo mencionar as perspectivas sistêmico-funcionalistas, a teoria da mobilização de recursos, a corrente da mobilização política, os enfoques neomarxistas, as vertentes acionalistas-culturalistas e o debate acerca da noção de reconhecimento.

Essa miríade de perspectivas possibilitou a visualização de muitos dilemas analíticos, sendo que um dos mais debatidos refere-se à dicotomia ator x estrutura social. O cerne desse debate encontra-se na freqüentemente advogada necessidade de optar por um olhar micro ou macrossociológico (Alexander, 1988). Essa suposta necessidade de eleição de um dos pólos para compreender um movimento social é marcante em muitos estudos. Enquanto alguns frisam o papel dos indivíduos (sejam eles motivados por razões ou emoções), outros defendem o privilégio do processo histó116 rico e das oportunidades por ele geradas. A opção por um desses "pólos" leva, muitas vezes, à negligência do outro, sendo que a complexidade do fenômeno é reduzida pela busca de explicações causais.

O objetivo do presente artigo é apontar que os movimentos sociais não podem ser explicados nem por vontades, sentimentos e interesses de indivíduos, de um lado, nem pelas oportunidades encetadas pelo processo histórico, de outro. Há algo no cruzamento entre sujeitos e o contexto, que, por assim dizer, permite que uma noção de coletividade irrompa. Acreditamos que o conceito de acontecimento pode se mostrar um instrumento conceitual interessante para a compreensão desse "algo", já que ele dá conta tanto do poder hermenêutico do movimento como de sua certa casualidade, permitindo inscrever o fenômeno em uma dinâmica distinta daquela que é regida pela motivação individual e daquela que o concebe em termos de encadeamentos históricos. 
Até o momento, o conceito de acontecimento tem sido muito utilizado em estudos acerca dos meios de comunicação e, mais especificamente, em pesquisas sobre jornalis$\mathrm{mo}^{2}$. Entendendo o acontecimento como aquilo que é digno de conhecimento, e debruçando-se sobre os modos de tratamento discursivo que possibilitam a circulação dele sob a forma da informação, algumas pesquisas têm evidenciado a riqueza do conceito ${ }^{3}$. Diante da ruptura na ordem das coisas, os media procuram apreender o, inicialmente, incompreensível, buscando causas e conseqüências e estabelecendo comparações com situações semelhantes. Isso é, em geral, feito por meio da restrição do acontecimento à sua efetuação espaço-temporal (o fato $)^{4}$.

Embora reconhecendo a riqueza do conceito na análise das narrativas midiáticas, gostaríamos de chamar a atenção para a proficuidade de estendê-la para estudos referentes a outros fenômenos. Assim, nosso enfoque se volta, especificamente, para a questão dos movimentos sociais.

\footnotetext{
${ }^{2}$ Um dos primeiros a se dedicar a essa questão foi Pierre Nora (1972), para quem um acontecimento só é um acontecimento se é conhecido. Nas sociedades contemporâneas, é por meio dos media que isso se faz possível, sendo que as narrativas midiáticas seriam as responsáveis por tornar o acontecimento monstruoso, ao se basearem na redundância e na produção do sensacional. O autor defende que a pregnância midiática do acontecimento representaria um esvaziamento de seu caráter extraordinário e geraria alienação.

${ }^{3}$ Para alguns exemplos recentes, ver Mouillaud (2002), Charaudeau (1997), Champagne (2000), Berger (2006), França e Almeida (2006), Ponte (2006), Martins (2006).

${ }^{4}$ Para Mouillaud (2002), a explosão de sentido acarretada pelo acontecimento é emoldurada de modo a reduzir sua complexidade. Ao enquadrá-lo, os profissionais da mídia não podem senão esquartejá-lo, ressaltando apenas algumas de suas facetas. Enfocando a potência diegética do acontecimento, Charaudeau (1997) afirma que esse cerceamento da hemorragia de sentidos do acontecimento não se deve a uma vontade específica dos profissionais da mídia. Trata-se de um processo social que envolve não apenas rotinas de tratamento, mas também os enquadramentos mais amplos que regem a vida social. O que se passa no mundo ganha sentido através de uma estruturação que é dada pelo próprio ato de linguagem, o qual só existe por meio de um vínculo entre sujeitos. A interpretação do acontecimento - manifesta na linguagem - apóia-se, ao mesmo tempo em que atualiza, numa intersubjetividade que não se restringe à situação.
} 
Interpretar um movimento social a partir do conceito de acontecimento é percebê-lo como descontinuidade que irrompe no tecido social, permitindo a reinterpretação de elementos que o precederam e dos campos de possibilidade que o sucederão. Ao reconfigurar, interpretativamente, fragmentos da realidade social, tais agências coletivas afetam o contexto em que se situam e os próprios sujeitos que as constituem, ao mesmo tempo em que são por eles edificadas.

Nesse sentido, a proposta é conceber a própria configuração da coletividade como um acontecimento, percebendo que ela se desdobra em várias ações, que podem ser compreendidas como microacontecimentos, desencadeadas e possibilitadas pela existência desse acontecimento mais amplo (i.e., o movimento social). Com essa discussão, buscamos caracterizar a dimensão de agência dessas coletividades, que não podem ser compreendidas apenas como atores. Movi118 mentos não são, simplesmente, entidades que se apresentam, publicamente, em defesa de certas causas ou sujeitos. Ainda que, freqüentemente, assim se apresentem e necessitem dessa sistematização para tornarem-se reconhecíveis, na base de sua configuração, há um devir accional e heterogêneo que pode ser elucidado a partir da idéia de acontecimento.

Iniciaremos nossa discussão com uma sucinta apresentação do conceito de acontecimento, orientando-nos, principalmente, pelas idéias de Louis Quéré. Em seguida, buscaremos estabelecer algumas relações entre tal conceito e os movimentos sociais, ressaltando a relevância das noções arendtianas de ação e refundação. Procuraremos, então, evidenciar o caráter de acontecimento dos desdobramentos públicos das lutas de um movimento, com base na noção de esfera pública. Discorreremos, por fim, sobre o freqüente processo de cristalização dessa agência coletiva na burocratização de uma entidade que se quer unificada. 


\section{A construção simultânea do passado e do futuro}

É comum falarmos sobre os acontecimentos que atravessam nossas vidas. Contamos a amigos e familiares aquilo que se passou conosco nos últimos tempos. Conversamos sobre os acontecimentos que nos chegam pelos media. Registramos alguns deles em livros de memória e de história. Mas a própria noção de acontecimento parece, muitas vezes, reduzida à idéia de fato: aquilo que se passou no mundo, sendo causado por ocorrências determinadas e tendo conseqüências apreensíveis e mensuráveis. Nosso espanto diante de um acontecimento é logo sucedido por uma espécie de calmaria que reflete o conforto em ver a regularidade da realidade restabelecida.

Também as ciências sociais têm dificuldade em lidar com a noção de acontecimento, o que se deve, segundo Louis Quéré, a várias razões:

Uma delas tem a ver com o facto das ciências sociais tenderem a associar a acção a sujeitos movidos por razões de agir, por motivos ou por interesses, e menos a uma afecção por acontecimentos e por mudanças, nos objectos ou nas situações, no decurso da própria organização da experiência. Uma outra é que as ciências sociais apreendem, sobretudo, o acontecimento, como integrante da categoria do facto e recorrendo ao esquema da causalidade, hesitando em tratá-lo como fenômeno de ordem hermenêutica. (2005, p. 59-60)

É mais promissora a perspectiva que encara o acontecimento como uma espécie de ruptura na continuidade da experiência, que afeta os sujeitos ao mesmo tempo em que é afetado por eles. Dotado de certa autonomia, o acontecimento cria as condições para sua compreensão e contém um caráter revelador ao alterar tanto as possibilidades de leitura do passado (daquilo que o causou) como do futuro (à 
medida que ele inaugura campos de possíveis concebíveis). Em suas incursões filosóficas sobre a lógica do sentido, Gilles Deleuze (1975) defende que o acontecimento é o puro tornar-se : trata-se de um louco devir ilimitado que não pode ser fixado em substantivos ou adjetivos. Ele é a transformação em si, a ocorrência em desenvolvimento: algo da ordem do verbo no infinitivo. Assim, ele não pode ser situado no passado, já que não se trata do ocorrido. $\mathrm{O}$ acontecimento, tal como Janus ${ }^{5}$, olha concomitantemente, para frente e para trás, situando-se no entre-lugar não apreensível daquilo que o presente vem a ser ininterruptamente. Ele transborda o passado e o futuro, agindo nas duas direções ao atuar como uma superfície sem espessura que separa e liga os dois ${ }^{6}$.

Partindo da concepção de linguagem dos estóicos, Deleuze afirma que o sentido de manifestações lingüísticas é um acontecimento, visto não existir nem nas coisas, nem nas palavras, nem nas imagens às quais estas se referem. O sen120 tido não é determinado nem no ato da designação (relação das palavras a um estado de coisas), nem na manifestação (relação da proposição ao sujeito que fala), nem na significação (relação da palavra com conceitos gerais). Ele surge, emerge, na fina lâmina situada entre o mundo, as palavras e as pessoas. $\mathrm{O}$ "sentido é o expresso da proposição, este incorporal na superfície das coisas, entidade complexa irredutível, acontecimento puro que insiste ou subsiste na proposição" (Deleuze, 1975, p. 20). Ele não está dado a priori pelo sujei-

\footnotetext{
${ }^{5}$ Divindade mitológica romana, cuja principal função era a de porteiro celestial, Janus tem duas faces, que representam seu olhar permanente em duas direções: o lado de fora e o de dentro, o passado e o futuro. Ele simboliza o constante ato de fechar e abrir que marca o nascimento de algo novo. O nome do mês de Janeiro é uma homenagem a essa divindade, por se tratar do mês de passagem de um ano a outro.

${ }^{6} \mathrm{O}$ acontecimento, segundo Deleuze, pertence à categoria temporal que os estóicos chamavam de Aion: tempo não-fixado, pontual, do presente sem espessura "que não cessa de dividir a linha e de se dividir a si mesmo em passado-futuro" (Deleuze, 1975, p. 153). Trata-se do oposto de Cronos, o tempo linear e seqüencial.
} 
to, nem existe como estado definitivo, mas acontece em uma dada situação. O "eu" não diz o sentido do que diz.

Adotando um olhar mais sociológico, Louis Quéré (2005) também se preocupa com o conceito de acontecimento, buscando destituir a idéia de um sujeito onipotente, que significa o mundo de acordo com suas visões e valores. Quéré afirma que o acontecimento tem um poder hermenêutico capaz de revelar, simultaneamente, passados e futuros. Baseando-se nas idéias de Hannah Arendt, ele lembra que o acontecimento tem um caráter inaugural: ao emergir, ele tem "poder de abertura e fecho, de iniciação e de esclarecimento, de revelação e de interpelação" (2005, p. 60). O autor defende que o acontecimento introduz uma descontinuidade, excedendo as possibilidades do previamente calculado. No entanto, tão logo ele surge, os sujeitos buscam restabelecer a continuidade do mundo, procurando, no passado, anúncios de sua ocorrência. Esse passado não existia, todavia, antes do acontecimento: ele é revelado e esclarecido pelo próprio acontecimento. É “produzindo-se que ele manifesta a sua possibilidade e que revela diferentes potencialidades (porque as actualizou) e eventualidades (porque é possível inferi-las do que se passou) preexistentes" (Quéré, 2005, p. 7).

Da mesma forma que cria as condições para a sua própria compreensão, o acontecimento também instaura possíveis futuros. Possivel, lembra Quéré com Granger, é aquilo que é susceptível de vir a se tornar experienciável pelos sujeitos, embora ainda não o seja. Nos termos do autor, trata-se do não-atual em relação com o atual. A "abertura dos possíveis 'praticamente acessíveis' releva da própria dinâmica do desenvolvimento de uma situação (incluindo as expectativas e os projectos dos sujeitos)" (Quéré, 2005, p. 64). O agora confere, portanto, sentido tanto ao que se passou como ao que pode vir a se passar. Ele institui, ao mesmo tempo, passado e futuro. 
Importante destacar, aqui, a questão da passibilidade do acontecimento. Segundo Quéré (2005), o acontecimento acontece a alguém: ele afeta os sujeitos, toca-os. Tem efeitos que são da ordem do sentido. Ele pode, portanto, alterar as práticas sociais, os campos de ação e a vida dos sujeitos, reestruturando a experiência. O indivíduo não é o dono da significação do mundo: ele sofre os efeitos do acontecimento, ainda que também responda a ele, em uma relação de codeterminação. "A individualidade do acontecimento não é determinada, apenas, pelas características da sua ocorrência como facto, mas também pelas reacções e pelas respostas que suscita, via uma compreensão e uma apropriação, seja qual for o suporte" (Quéré, 2005, p. 68).

No sentido estrito da idéia de causalidade, portanto, o acontecimento não é causado nem causa nada. Ele não é uma entidade que está ao início ou ao final de uma cadeia linear e unilateral. O "acontecimento e aquele a quem ele acontece são, ambos, coisas que 'se tornam' no quadro de uma transação" (Quéré, 2005, p. 68). Se os sujeitos podem reconfigurar o acontecimento à medida que dele se apropriam interpretativamente, esse poder é limitado, já que, em alguma medida, ele não depende de nós. O acontecimento carrega sentido, transforma o próprio campo de percepções daqueles a quem afeta, abrindo novos horizontes. É justamente aí que reside seu poder de revelação: o acontecimento possibilita uma alteração dos quadros de compreensão do self e do mundo.

O acontecimento aparece, assim, como uma singularidade problematizante, como já assinalava Deleuze (1975): ele reconfigura o mundo, restabelecendo uma continuidade diferente da imaginada antes de sua ocorrência. Quéré sugere que, se pensarmos a experiência dos sujeitos no mundo como uma trama (intriga), que não é inteiramente controlada por eles, será possível perceber como campos problemáticos, repletos de tensões, emergem nos cruza- 
mentos de muitos dos fios do viver. Nesse sentido, "novos campos problemáticos se constituem com a emergência de acontecimentos, nomeadamente a partir do trabalho realizado em torno deles, explicitando o que está em causa, no âmbito da regulação política das condições de viver-conjuntamente numa colectividade" (Quéré, 2005, p. 72). À medida que revela um mundo novo, o acontecimento faz com que o próprio passado não apareça como coisa explicada, mas como explicável porque ainda se desenrolando em um campo problematizante. O futuro também se vê alterado, visto que possíveis são por ele abertos, demandando que os sujeitos se posicionem acerca deles. Instauram-se campos problemáticos, portanto, porque a maneira do acontecimento se abater sobre os sujeitos é a do deslocamento.

A noção de acontecimento, como já mencionado, tem sido bastante mobilizada em estudos acerca da ação dos media. Entendemos, todavia, que ela pode mostrar-se um instrumento conceitual acurado para dar conta de uma multiplicidade de fenômenos. Nosso objetivo neste artigo é pensar, especificamente, como a noção pode ser adotada para a análise de movimentos sociais. Diferentemente das perspectivas que julgam que os movimentos sociais são puros reflexos de acontecimentos que lhe seriam externos (como ações de sujeitos ou eventos históricos), entendemos que os próprios movimentos podem ser pensados sob a ótica do acontecimento. É o que buscaremos desenvolver na próxima seção.

\section{0 acontecimento: ação e refundação em Hannah Arendt}

A chave para pensar o caráter acontecimental da noção de movimentos sociais está em seu poder hermenêutico. Se o acontecimento é essa descontinuidade inesperada que se abate sobre os sujeitos e sobre o mundo, permitindo que passado e futuro sejam simultaneamente reconstruídos, movimentos podem claramente ser pensados a partir dessa catego- 
ria. Isso não apenas porque tais coletividades se formam de maneira não previsível no encontro de sujeitos com as oportunidades e recursos contextualmente localizados (Honneth, 2003). Mas também porque é o próprio emergir da coletividade que permite a constituição do passado como marcado por práticas desrespeitosas e do futuro como espaço de construção de outros mundos possíveis.

É por isso que Melucci (1996; 2001) define os movimentos como profetas: eles não são o resultado de uma crise, mas o sinal (e o motor, poderíamos acrescentar) de transformações profundas. É insuficiente dizer que os movimentos surgem como lutas contra situações de injustiça e desrespeito, porque, muitas vezes, é só com a constituição da coletividade que tais situações são passíveis de ser percebidas como desrespeitosas. Movimentos atuam como a superfície sem espessura de que falava Deleuze (1975): instaurando um presente pontual, eles criam um campo problematizante ao deslocar enten124 dimentos profundamente enraizados acerca tanto daquilo que éramos como daquilo que podemos nos tornar. Entendimentos esses que versam tanto sobre a autocompreensão dos sujeitos como sobre a sociedade como um todo.

O pensamento de Hannah Arendt pode mostrar-se bastante esclarecedor para o entendimento dessas questões. Ao buscar compreender o acontecimento do totalitarismo, em sua originalidade, Arendt alega que, diante daquilo que não tem precedentes, somos como que inábeis para produzir significado. A filósofa frisa que o acontecimento tem um caráter revelador, trazendo "à luz a ruína de nossas categorias de pensamento e de nossos padrões de juízos” (1993, p. 49). Ele não pode ser explicado pela causalidade, justamente porque novo: "Somente quando algo irrevogável aconteceu é que podemos retraçar sua história. $\mathrm{O}$ acontecimento ilumina o próprio passado; jamais pode ser deduzido dele" (1993, p. 49). Ele permite reconstituir o antes em uma narrativa, possibilitando que se veja nele um começo até então 
oculto. Assim, "no momento em que se dá um evento, até mesmo quando ele é antevisto, tudo muda sem que jamais possamos estar preparados para a inexorável literalidade desse "tudo"” (1993, p. 50).

É na categoria da ação que Arendt (2005) situa a capacidade humana de gerar algo novo - de produzir acontecimentos -, sendo que a idéia de origem é central para o pensamento político. Importante destacar, aqui, que a definição arendtiana de ação não está calcada no primado do sujeito. Não se trata de um retrocesso ao indivíduo consciente e senhor de si, capaz de agir instrumentalmente com base em cálculos de custos e benefícios. Dotada de grande sofisticação filosófica, a noção é a base do pensamento político de Arendt.

Em explícita discordância com a tradição platônica, Arendt busca ressaltar a importância da Vita Activa $a^{7}$, definindo as três atividades que a constituiriam: labor, work e action (labor, trabalho/obra e ação). A primeira se refere às atividades de reprodução do ciclo biológico do corpo humano. De curto prazo, elas não têm durabilidade, esgotando-se em si mesmas. Work, por sua vez, diz respeito à produção de um mundo artificial de coisas, contando com uma certa, ainda que limitada, durabilidade. Action, por fim, é uma atividade que só pode ser exercida entre homens. Mediada pelo simbólico, ela tem permanência e sobrevive à vida dos indivíduos singulares. A ação está baseada na pluralidade, ao mesmo tempo em que a gera: "A pluralidade é a condição da ação humana pelo fato de sermos todos os mesmos, isto é, humanos, sem que ninguém seja exatamente igual a

\footnotetext{
${ }^{7}$ Cabe mencionar que as críticas freqüentemente endereçadas a Arendt por desconsiderar os aspectos da ordem da representação e da atividade mental parecem desconhecer o esforço iniciado pela autora em The life of the mind. Mesmo em $A$ condição humana, a autora já antecipa essa questão ao afirmar: "o uso que dou à expressão vita activa pressupõe que a preocupação subjacente a todas as atividades não é a mesma preocupação central da vita contemplativa, como não lhe é superior nem inferior" (2005, p. 26).
} 
qualquer pessoa que tenha existido, exista ou venha existir" (Arendt, 2005, p. 16).

A ação se refere à permanente constituição intersubjetiva de um mundo humano. "O mundo no qual transcorre a vita activa consiste em coisas produzidas pelas atividades humanas; mas, constantemente, as coisas que devem sua existência exclusivamente aos homens também condicionam os seus autores humanos" (Arendt, 2005, p. 16). Os sujeitos se inserem em teias de significação preeestabelecidas, mas podem atuar sobre tais teias na medida em que agem, já que agir "significa tomar iniciativa, iniciar [...] imprimir movimento a alguma coisa" (Arendt, 2005, p. 190). A ação, sempre compreendida simbolicamente ${ }^{8}$, é o que permite que a sociedade crie, coletivamente, novos começos e se refunde. Ela não é, portanto, algo factível individualmente: depende do outro, visto ser relacional e intersubjetiva. Ela "não pode sequer ser imaginada fora da sociedade dos homens" (Arendt, 2005, p. 31).

Tendo em vista essa acepção, movimentos sociais podem ser interpretados como o puro exercício da ação. Ao irromper na vida social, eles inauguram algo de novo, questionando o que até então parecia natural. Construindo novos quadros de interpretação da realidade, movimentos jogam luz tanto sobre o passado como sobre o futuro (Melucci, 1996), buscando tornar-se divisores de águas capazes de alterar a ambos. Pode-se dizer, em suma, que eles criam o novo, que é imprevisível, dada a condição humana da natalidade.

\footnotetext{
${ }^{8}$ Arendt defende que o medium de realização da ação é, por excelência, a palavra. Ainda que os gregos, cuja tradição é o alicerce da filosofia arendtiana, usem termos distintos para práxis e léxis, a autora lembra que estes eram tidos como uma unidade, "e isto significava não apenas que quase todas as ações políticas [...] são realmente realizadas por meio das palavras, porém, mais fundamentalmente, que $o$ ato de encontrar as palavras adequadas no momento certo, independentemente da informação ou comunicação que transmitem, constitui uma ação" (2005, p. 35).
} 
Movimentos revelam o mundo, no sentido que James Bohman (1996) atribui ao termo em diálogo com a concepção heideggeriana de disclosure. De acordo com Bohman, atores críticos podem revelar novos mundos sociais e formas de interação ao buscar desestabilizar elementos das redes tácitas de significação que os cercam. Ele destaca que revelação não tem nada a ver com fazer emergir a verdade: "tem mais a ver com a abertura de novas possibilidades de liberdade humana e agência transformativa. Revelação designa mudança radical na interpretação do mundo" (Bohman, 1996, p. 213). Se os códigos culturais naturalizam construções sociais, movimentos podem desconstruí-las, criando um contexto em que novos valores e práticas sejam vistos como possíveis.

Importante perceber que essa revelação afeta tanto os sujeitos que a desencadeiam como a sociedade como um todo, dada a passibilidade do acontecimento. Arendt (2005, p. 196) deixa claro que a própria identidade dos indivíduos é revelada (no sentido de construída) por meio da ação discursiva junto aos outros. Ao tratar a questão dos movimentos sociais, Honneth destaca esse aspecto, afirmando que "o engajamento nas ações políticas possui para os envolvidos também a função direta de arrancá-los da situação paralisante do rebaixamento passivamente tolerado e de lhes proporcionar, por conseguinte, uma auto-relação nova e positiva" (2003, p. 259). Alteram-se, assim, os próprios parâmetros que orientam a experiência de tais sujeitos.

No que concerne a afetar a sociedade, nota-se, como já dito, que o movimento busca revelar uma outra realidade (com seus próprios passados e seus campos de possibilidades futuras). Isso porque o fruto da ação discursiva entre homens é a atualização e a reconfiguração de um mundo comum, no qual nos inserimos ao nascer. "É isto o que temos em comum não só com aqueles que vivem conosco, mas também com aqueles que aqui estiveram antes e aqueles que virão depois de nós" (Arendt, 2005, p. 65). 
A ação de movimentos sociais pode ser analisada, pois, como uma proposta de refundação. Trata-se de uma interrupção do curso automático da vida, por meio do surgimento de interpretações inesperadas que propõem novos modos de convivência. Arendt defende essa infinita capacidade humana de começar, caracterizando-a como "a liberdade de chamar à existência o que antes não existia, o que não foi dado nem mesmo como um objeto de cognição ou de imaginação e que não poderia, portanto, estritamente falando, ser conhecido" (Arendt, 1992, p. 198). Ainda segundo ela, é "da própria natureza de todo novo início o irromper no mundo como uma 'improbabilidade infinita', e é, contudo, justamente esse infinitamente improvável que constitui de fato a verdadeira trama de tudo que denominamos de real" (Arendt, 1992, p. 218).

Esse irromper do novo - que reflete a capacidade humana de contínua e perpetuamente regenerar-se (Arendt, 128 1988, p. 169) - só pode ser feito coletivamente. O ato de criação só se dá em relação mútua, no espaço intermundano. É só em interlocuções com a sociedade que os movimentos podem esperar ver realizado o nascimento de uma nova ordem, ou a refundação da sociedade. É só ao interagir com atores que lhe são externos que o movimento pode sugerir novos padrões de interação. Apenas no espaço interacional que o liga aos outros (incluindo aqueles que o precederam e aqueles que o sucederão) pode atualizar os pactos que regem a vida social.

Vale ressaltar que esse processo de criação do novo e de refundação da aliança social não é um ato de vontade nem se encontra sob a direção do intelecto. Não se trata do ato puro e simples de um movimento como coletividade, nem dos integrantes que o constituem. Isso porque "o ator nunca é simples 'agente', mas também, e ao mesmo tempo, paciente. Agir e padecer são como as faces opostas da mesma moeda, e a história iniciada por uma ação compõe-se de 
seus efeitos e dos sofrimentos dele decorrentes" (Arendt, 2005 , p. 203). Entender um movimento social como acontecimento é perceber que a irrupção da novidade não parte de, nem é controlada por, atores específicos. Brunkhorst (2000, p. 188) capta bem essa dimensão da visão arendtiana quando lembra que toda ação ocorre dentro de uma situação histórica na qual os indivíduos são, involuntariamente, lançados. Tudo o que fazem ocorre em relação a essa situação.

$\mathrm{O}$ acontecimento, no caso um movimento, não é só resultado da atitude de sujeitos, nem simplesmente causa tais atitudes. Há um jogo recursivo aqui, evidenciado pela incapacidade do homem de controlar e prever as conseqüências da novidade de cuja produção participa (Arendt, 2005, p. 247). Nesse sentido:

É da própria natureza de um início conter, em seu âmbito, uma certa dose de arbítrio. Além de não estar preso a nenhuma cadeia explícita de causa e efeito, uma cadeia na qual cada efeito se transforma imediatamente na causa de futuros desdobramentos, o início parece não ter nada em que se apoiar; é como se ele surgisse de um vazio fora do tempo e do espaço (Arendt, 1988, p. 165).

Movimentos sociais emergem no encontro quase que inexplicável e imprevisível entre um conjunto de sujeitos (dotados de certas emoções e razões) e uma conjuntura sociopolítica, econômica e cultural. Dessa situação, surgem quadros interpretativos que abrem o passado de maneiras inesperadas, fazendo com que futuros nunca dantes imaginados sejam colocados como possibilidades passíveis de construção. No presente, tal como o Aion estóico a que se refere Deleuze, eles abrem campos problemáticos, convocando a sociedade a se repensar e a se refundar com base em outros padrões interacionais. O sentido desses futuros não é determinado pelos sujeitos, mas pela complexa dinâ- 
mica de interações e interlocuções entre os integrantes de tal coletividade, outros atores sociais e elementos contextuais que não são controlados pelos atores.

É por isso que a "constituição e a evolução de um campo problemático público são processos complexos, em grande parte entregues à contingência” (Quéré, 2005, p. 22). Como bem adverte Lança (2006, p. 91), a configuração de tal campo depende dos jogos discursivos de que participam diversos atores em diferentes arenas, sendo que as respostas dos públicos são, de algum modo, imprevisíveis. O impacto desse devir em direção a um novo pacto social depende, pois, da geração de vários microacontecimentos em uma esfera pública. É este o aspecto a ser trabalhado na última seção do presente artigo.

\section{0 acontecimento se desdobra: discurso e esfera pública}

Sendo um movimento social entendido pela ótica do acontecimento, em que consiste sua atuação? Como pode ele atuar no sentido de revelar mundos passados e mundos possíveis? De que modo a emergência de um movimento pode estender-se para além do momento efêmero em que sua criação é vislumbrada?

Para responder a essas questões, faz-se necessário atentar para a capacidade de autodesdobramento do acontecimento. A agência de um movimento social é o próprio desdobrar da potência de ruptura contida na descontinuidade emergente, visto haver no acontecimento algo que permanece em aberto - um não-atualizado que só se estabelece progressivamente. Se a ação representa um começo, tal início se prolonga no surgimento de outras ações, sempre efetuadas no espaço intersubjetivo criado relacionalmente. $\mathrm{O}$ acontecimento mais geral (i.e., o próprio movimento social) desenrola-se em uma série de microacontecimentos (discursos, atos, manifestações), sem os quais aquele não existiria. Em uma dinâmica recursiva, é a própria ruptura proporcionada pelo 
surgimento de um movimento que permite a constituição de determinados discursos, interpretações e ações, sendo que estes são a própria base da existência da ruptura. Para compreender essas questões, é mister refletir, brevemente, sobre a noção de esfera pública, já que esta toma forma através do pulular intersectante de microacontecimentos dotados de significação.

Hannah Arendt (2005) define a esfera pública como o que há de comum aos homens. Ela lembra que o termo remete a dois fenômenos correlatos: 1) o espaço daquilo que pode ser visto e ouvido por todos; e 2) o mundo comum atualizado pelos homens na ação. Para ela, o aparecer aos outros é o alicerce da realidade partilhada, cuja expressão e construção dependeriam de uma pluralidade de olhares. É com base nessa pluralidade que se institui o mundo intersubjetivo, o qual coloca os sujeitos em relação, ao mesmo tempo que os distingue. Construído discursivamente, tal mundo é a teia de sentidos e relações que nos precede e nos sucede, mas sobre a qual podemos deixar nossas marcas.

Jürgen Habermas $(2003 ; 1992 ; 1997 ; 2002)$ também trabalha a noção de esfera pública a partir de sua tessitura linguageira. Operando com um conceito normativo de esfera pública, o filósofo alemão o coloca no cerne da construção social da realidade e do agir político dos sujeitos. Habermas define tal esfera como uma rede comunicativa que é formada por - ao mesmo tempo que possibilita - um cruzamento de discursos justificados por razões. Trata-se de uma instância de choque de argumentos em público, sendo que a publicidade deve garantir não apenas a circulação desses argumentos, mas também o seu escrutínio de modo que prevaleça a força do melhor argumento. Concretizada em várias arenas temáticas que se atravessam, a esfera pública é o locus em que se processa o bem comum e o esclarecimento recíproco dos cidadãos. Nessa rede discursiva, questões são 
publicamente tematizadas e refinadas com base nos códigos amplamente partilhados da linguagem cotidiana ${ }^{9}$.

Seguindo a trilha de Habermas, Charaudeau (1997) define a esfera pública ${ }^{10}$ como o espaço de representação, partilha e discussão. Preocupado, sobretudo, com a constituição sociolinguageira de tal esfera, ele lembra que a criação de um âmbito comunicacional compartilhado é algo de suma relevância para a própria existência da sociedade. Ele lembra que um grupo social "tem necessidade de regular suas trocas segundo regras de classificação dos objetos, das ações e de normas de julgamento. É preciso, portanto, que [...] produza discursos de avaliação, e que, fazendo-os circular, instaure uma partilha de suas representações" (Charaudeau, 1997, p. 111). Dinâmica e plural, a esfera pública é, para Charaudeau, uma espécie de discurso circulante, por meio do qual se travam lutas por poder e se regula a cotidianidade social.

Também partindo da base habermasiana, Quéré (1995) afirma que a esfera pública não pode ser resumida como discussão, mise en scène ou acessibilidade generalizada. De acordo com ele, é preciso frisar a dimensão praxiológica da esfera pública, ou seja, sua construção no próprio momento do encontro de enunciações. Para tanto, Quéré (1995, p. 94) propõe que a esfera pública seja considerada como forma ${ }^{11}$, o que quer dizer que ela estrutura a coexistência e configura as relações sociais. Falar da esfera pública como forma é per-

\footnotetext{
${ }^{9}$ Se, nos primeiros trabalhos de Habermas (sobretudo em Mudança estrutural da esfera pública), essa esfera era pensada como situada entre o Estado e a sociedade civil, nos textos mais recentes ela ganha contornos mais extensos, intersectando tanto os sistemas funcionais da economia e política como o mundo da vida (Lebenswelt), no qual está fundada.

${ }^{10}$ Cabe mencionar que o autor utiliza a expressão espaço público em vez de esfera pública. A idéia a que se refere é, no entanto, a mesma que temos em mente, sendo que tal substituição se deve às próprias traduções da obra habermasiana em língua francesa. Julgamos ser preferível o termo esfera em virtude de ele não ter uma conotação de lugar físico. Esse apontamento vale também para o trabalho de Louis Quéré, a ser discutido abaixo.

${ }^{11}$ Ao falar de forma, Quéré não pretende tratar a esfera pública como abstração, mas como um princípio de organização e um contorno.
} 
ceber o jogo recursivo dessa instância com os discursos que a compõem. Ao mesmo tempo que tal esfera só se configura no momento em que discursos publicamente acessíveis se intersectam, esses discursos são produzidos a partir das regras pragmáticas e princípios organizatórios que regem a esfera pública. Instituída na efetuação do falar, ela retroage sobre essa fala, conformando-a. Trata-se, pois, de uma idéia reguladora que anima, guia e articula práticas sociais. A esfera pública é um princípio de organização que porta uma potência formante : ela organiza o substrato que permite o configurar da ação e da relação. Recursivamente, ela aparece como produto mesmo das práticas que suscita e condiciona, estruturando as práticas das quais emerge (Quéré, 1995, p. 98).

As ações de movimentos sociais se desdobram nesse espaço simbólico interacionalmente gestado da esfera públi$c a$. Para propor a refundação da sociedade (seja ela uma reestruturação profunda ou a alteração de aspectos pontuais), tais movimentos precisam construir coletiva e intersubjetivamente outros sentidos sobre si mesmos, sobre o mundo e sobre as relações sociais. Isso é feito por meio de trocas argumentativas públicas, sendo que a publicidade não se resume à visibilidade propiciada pela enunciação: ela é algo que conforma o próprio ato de expressar-se diante dos outros. O estar em relação impõe constrangimentos e regras de conduta, sendo que há argumentos que não podem ser defendidos publicamente. Argumentos válidos na esfera pública, como lembra Habermas (1992, 1997, 2002), precisam justificar-se por meio de razões públicas, o que implica a consideração das perspectivas dos demais participantes em um processo marcado pela reciprocidade.

É interessante conceber os movimentos, portanto, como enunciadores que colocam o mundo em linguagem, buscando narrativizá-lo de formas alternativas àquelas tradicionalmente feitas. Ao enunciar novos mundos e defender 
a possibilidade deles, movimentos desdobram a inovação mais geral que representam (contida em sua própria configuração) em microacontecimentos desestabilizadores. Os discursos por ele produzidos irrompem na esfera pública, instaurando a crítica, em que tudo parecia natural. Cada ato discursivo proferido emerge da teia tácita de significação socialmente compartilhada, colocando em evidência aspectos que podem permitir a reinterpretação de causalidades passadas e de futuros possíveis.

Cabe esclarecer que as idéias aqui apresentadas estão alicerçadas em uma concepção de discurso que tem por premissa o fato de sua construção ser atravessada por algo que é externo ao código lingüístico. De origem pragmática, tal premissa é defendida por autores tão distintos como Foucault, Verón, Charaudeau, Quéré e Habermas. Todos eles buscam, de algum modo, restituir aos discursos sua dimensão de acontecimento, descentrando a originalidade do indiví134 duo criador e lembrando que o sujeito fala aquilo que pode ser dito em uma dada época, ainda que inove a partir dessa matriz. Tanto o sujeito como os discursos constituem-se na rede semiótica que não é controlada por ninguém, mas pelo jogo de recursividades imprevisíveis entre atores sociais, signos, interpretações e o contexto que os circunda.

Essas idéias ajudam a compreender o caráter de acontecimento dos discursos encetados por movimentos sociais. Em primeiro lugar, porque tais discursos não são produzidos - no sentido de originados - por tais atores. A manifestação discursiva não pode ser explicada por aquele que parece havê-la desencadeado. Ela se produz a partir das relações estabelecidas pelos integrantes de um movimento em uma série de âmbitos interacionais $^{12}$, sendo perpassada não apenas pelos atores com os quais interagem, mas também pelo contexto que emoldura tais relações. Em segundo lugar, porque

${ }^{12}$ Sobre a idéia de âmbitos interacionais, ver Mendonça (2006). 
essas manifestações discursivas não simplesmente reproduzem o contexto do qual emergem. Elas expõem fragmentos da tessitura social. Podem salientar, reinterpretar e criticar aspectos da planície subjacente de significação, fazendo surgir, numa espécie de orogênese semântica, cordilheiras capazes de reestruturar o relevo como um todo.

A idéia que, aqui, defendemos é, em suma, a de que existe uma matriz tácita de significação que orienta as ações dos sujeitos em suas vidas ordinárias, ao mesmo tempo que é por eles reinventada. Há um tecido sociocultural que atravessa a construção dos acontecimentos linguageiros, ao mesmo tempo em que é atravessado por eles. Essa matriz está no cerne da noção de frames em Goffman, do mundo comum em Arendt, do tiers symbolisant ${ }^{13}$ em Quéré e do Lebenswelt em Schütz e Habermas.

Essa teia tácita de significação que envolve os sujeitos os constitui, mas também é construída por eles. Construção essa que se dá por meio de sua materialização na esfera públi$c a$. Ao fazer com que fragmentos dessa teia intersubjetiva sejam sensíveis e experienciáveis, atos de linguagem podem explicitar sua existência, tornando-os passíveis de crítica. $\mathrm{O}$ desdobramento acontecimental de movimentos sociais está calcado, exatamente, nessa questão. Ao construir, publicamente, discursos sobre o mundo, eles evidenciam regras, padrões interacionais e significados profundamente enrai-

13. Cabe aqui, uma sucinta menção à noção de tiers symbolisant de Quéré, visto ser ela a menos conhecida entre as noções mencionadas. Especialmente devedor à interpretação habermasiana do Lebenswelt, o conceito de terceiro simbolizante referese a uma espécie de segundo-plano normativo e representativo, com base no qual a comunicação é construída. Quéré afirma que a comunicação se estabelece no cruzamento de dois planos - o da mensagem e o da meta-mensagem: "quando nós dizemos alguma coisa, nós também dizemos algo sobre o que dizemos” (Quéré, 1982 , p. 30). A enunciação contém tanto um enunciado proposicional como um enunciado que define a relação interpessoal ali estabelecida. Mas esses dois planos não esgotam o ato comunicativo. Há uma reflexividade de segunda ordem, proporcionada pelo terceiro simbolizante, que permite a conjunção dos dois planos, com suas diferenças. Esse tiers symbolisant é elaborado coletiva e permanentemente na atividade comunicacional. 
zados, tornando concebível a alteração destes. Se os acontecimentos induzem a ações, estruturando um campo de experiência, é porque problematizam o segundo-plano, as crenças e os hábitos compartilhados e tidos como dados. Eles podem contrariar, complexificar ou acelerar as tramas sociais (as intrigas) em curso (Quéré, 1995, p. 103), ao reforçar ou desatar alguns de seus nós.

Esse processo de revisibilidade reflexiva do tecido social, via acontecimentos de linguagem, permite a reconstrução intersubjetiva do mundo em suas várias dimensões. Habermas $(1983 ; 1990)$ defende que um conceito sociologicamente frutífero de ação precisa vislumbrar a existência de três mundos analiticamente distintos, ainda que empiricamente imbricados: o mundo objetivo (totalidade de entidades sobre as quais é possível produzir proferimentos verdadeiros); o mundo social (totalidade de relações interpessoais legitimamente reguladas); e o mundo subjetivo (totalidade de experiências do falante às quais ele tem acesso privilegiado) (Habermas, 1983, p. 100). Na ação comunicativa voltada para o entendimento mútuo, atores constroem atos de fala dotados de pretensões de validade. Isso significa que eles se apropriam do contexto pré-interpretado do mundo da vida (Lebenswelt) referindo-se a aspectos dos três mencionados mundos. Ao fazê-lo, levantam pretensões de verdade (adequação ao mundo objetivo), de correção (adaptação ao mundo social) e de veracidade (adequação a estados subjetivos), além da de compreensibilidade. A confirmação ou crítica de tais pretensões se dá no encontro com o outro.

Movimentos sociais não apenas questionam pretensões de validade levantadas por outros atores (esperando desconstruir fragmentos do mundo da vida), como também buscam construir novas (visando a constituir outros mundos possíveis). A idéia é que eles podem instaurar, discursivamente, descontinuidades na vida social, levando a que 
novos quadros de significação ganhem forma e, mesmo que temporariamente, sedimentem-se. Nos discursos que publicizam, buscam tornar inteligíveis outras interpretações de mundo, de valores, de vínculos sociais e de sujeitos. Fica claro, pois, que o caráter de acontecimento dos movimentos sociais se revela nesse desdobrar em outros acontecimentos dotados de significações transformadoras.

Isso ocorre em uma diversidade de âmbitos interacionais, que vão das interações mais cotidianas dos integrantes de um movimento a instâncias decisórias formais. Importante citar, aqui, o papel dos media como instância relacional de relevância fulcral na constituição da esfera pública. Ainda que os media não sejam a totalidade de tal esfera, as narrativas por eles produzidas e veiculadas configuram-se como um ambiente privilegiado de construção discursiva, de estabelecimento de interações e de individuação de acontecimentos $^{14}$. Embora apanhem apenas estilhaços da agência de movimentos, os media permitem um certo espraiamento desses estilhaços. Isso porque eles podem suscitar uma série de interlocuções tanto no espaço midiático como fora dele (Charaudeau, 1997). As narrativas midiáticas, como prática comunicativa de grande visibilidade, participam da construção e reconfiguração do mundo comum, atuando como uma das teias de relações nas quais os sujeitos estão enredados e perpassando outras teias.

\section{Considerações finais}

Este artigo buscou compreender os movimentos sociais a partir da ótica do conceito de acontecimento. Discutindo o

\footnotetext{
${ }^{14}$ Segundo Quéré: "Um acontecimento é individuado quando se define o que o especifica como acontecimento particular [...] e que o distingue de todo outro acontecimento" (1995, p. 100). A individuação é a inscrição do acontecimento na ordem social, por meio de sua significação segundo as formas simbólicas de uma cultura. Tal processo envolve as atividades de descrição, narrativização (mise en intrigue) e normalização (redução de sua contingência pela explicitação de seu caráter típico).
} 
caráter revelador de tais atores, procurou-se pensar o modo como eles representam possibilidades de refundação de aspectos da realidade socialmente compartilhada. Abordouse, também, a maneira como tal acontecimento se desdobra em outros acontecimentos linguageiros, por meio dos quais uma esfera pública ganha corpo e permite a reflexão acerca de fragmentos do tecido social que envolve os indivíduos. Acreditamos que essas categorias podem ajudar a entender o processo de surgimento e atuação de movimentos sociais, renovando esse campo de pesquisas que parece ter perdido parte de seu vigor depois do verdadeiro fetichismo revolucionário que marcou as décadas de 1970 e 1980. Paradoxalmente, elas permitem ver as potencialidades de tais atores, justamente por descentrá-los, evidenciando a intrincada teia de relações que marca a atuação deles.

$\mathrm{Na}$ trajetória conceitual desenvolvida ao longo do artigo, buscamos pensar os movimentos sociais não como atores, mas como forma de ação coletiva. Uma descrição mais acurada deles, contudo, deve ressaltar a permanente dialética entre esse caráter accional e sua configuração como ator social. Entendidos como acontecimento, em seu puro devir, movimentos são essa potência de ação que profetizam sobre o passado e o futuro, permitindo a permanente construção da realidade. Mas esse acontecimento, como qualquer outro, é muitas vezes apreendido em tentativas de explicação. Para que os sujeitos dêem conta desse devir transformador, o movimento é, em geral, narrativizado, sendo que uma identidade coletiva é construída ${ }^{15}$. Esta identidade procura estabelecer a coerência e a unidade, onde há apenas um processo de contínua transformação. A narrativa identitária, freqüentemente, cerceia o devir para torná-lo apresentável.

${ }^{15}$ A esse respeito, ver Melucci (1996), Gamson (1992), Friedman e McAdam (1992), Somers e Gibson (1994), Taylor (1997). 
Se esse processo tem a vantagem de inserir esse ator como interlocutor reconhecível nas tramas da esfera pública, pode, por outro lado, conduzir a engessamentos que congelam a pulsão de ruptura daquilo que era, a princípio, indeterminado. Nesse caso, a enunciação se converte em enunciado, à medida que o acontecimento é restringido ao acontecido. Tal dinâmica ajuda a entender o declínio de alguns movimentos sociais, quando de sua burocratização, caracterizada pela tendência a autopreservação (Melucci, 1996). O movimento pode acabar por se engessar em uma estrutura sólida que se quer coerente. Naturaliza-se uma face de apresentação que se torna automática e, como adverte Arendt:

Uma vez que os processos históricos e artificiais se tenham tornado automáticos, não são menos destruidores que os processos vitais naturais que dirigem nosso organismo e que em seus próprios parâmetros, isto é, biologicamente, conduzem do ser para o não-ser, do nascimento para a morte (Arendt, 1992, p. 217).

Não desejamos concluir com a defesa de que a narrativização identitária é, necessariamente, autodestrutiva. Entendemos que a construção de uma face e de uma trajetória histórica é absolutamente fundamental para as lutas de movimentos sociais. Defendemos, todavia, que tal identidade não pode se sobrepor ao caráter de acontecimento que está no cerne de um movimento e de sua luta. Não é à toa que essa forma de ação coletiva é denominada por uma das características intrínsecas ao devir: movimento. Ação e ator combinam-se em uma dialética recursiva que institui e possibilita o próprio fenômeno aqui em tela. Reduzir o movimento a uma ação é negligenciar sua institucionalização e suas tentativas de produzir uma autocoerência. Defini-los como reles atores, por outro lado, é perder sua dimensão de acontecimento. 


\section{Ricardo Fabrino Mendonça}

é doutorando do Programa de Pós-graduação em Comunicação Social da UFMG e pesquisador do EME (Grupo de Pesquisa em Mídia e Espaço Público)

\section{Referências bibliográficas}

ALEXANDER, J. 1988. "From reduction to linkage: the long view of the micro-macro debate". In: Action and its environment. New York: Columbia University Press, pp. 257-298.

ALEXANDER, J. 1998. "Ação coletiva, cultura e sociedade civil - Secularização, atualização, inversão, revisão e deslocamento do modelo clássico dos movimentos sociais”. RBCS, vol. 13, n 37, pp. 5-31.

ARENDT, H. 1992a. "O que é autoridade". In: Entre o passado e o futuro. $3^{\mathrm{a}}$ ed. São Paulo: Perspectiva, pp. 127-187. 1992b. "O que é liberdade". In: ro. $3^{\text {a }}$ ed. São Paulo: Perspectiva, pp. 188-220. _. 1993. "Compreensão e política". In: Entre o passado e o futuA dignidade da polí tica. Ensaios e conferências. Rio de Janeiro: Relume-Dumará, pp. 39-53. 1998. Da revolução. Brasília/São Paulo: UnB/Ática. 2005. A condição humana. $10^{\mathrm{a}} \mathrm{ed}$. Rio de Janeiro: Forense.

BERGER, C. 2006. "O caso Aracruz. Do fato ao acontecimento jornalístico (um outro, o mesmo)”. Unirevista, São Leopoldo, vol. 1, nº 3.

BOHMAN, J. 1996. Public deliberation: pluralism, complexity and democracy. Cambridge: MIT.

BRUNKHORST, H. 2000. "Equality and elitism in Arendt". In: VILLA, D. (ed.). The Cambridge companion to Hannah Arendt. Cambridge: Cambridge University Press, pp. 178-198.

CHAMPAGNE, P. 2000. "L'evenement comme enjeu". Réseaux, Paris, CNET, $\mathrm{n}^{\circ} 100$, pp. 405-425.

CHARAUDEAU, P. 1996. "Para uma nova análise do discurso". In: CARNEIR0, A. D. (org.). O discurso da mídia. Rio de Janeiro: Oficina do autor, pp. $5-43$.

1997. Le discours d'information médiatique - La construction du miroir social. Paris: Nathan.

2004. "Comment le language se noue à l'action dans un modèle socio-communicationnel du discours. De l'action au pouvoir". Cahiers de linguistique française, Genève: Départment de Linguistique, $\mathrm{n}^{\circ}$ 26, pp. 151-175.

DELEUZE, G. 1975. Lógica do sentido. São Paulo: Perspectiva. 
FOUCAULT, M. 2001. A ordem do discurso. $7^{\mathrm{a}}$ ed. São Paulo: Loyola..

FRANÇA, V. R. V.; ALMEIDA, M. A. V. 2006. "O caso Fernanda Karina: as potencialidades do acontecimento". Texto apresentado no VIII Colóquio Brasil-França (Université Stendhal-Grenoble III).

FRASER, N; HONNETH, A. 2003. Redistribution or recognition? A political-philosophical exchange. Londres/Nova York: Verso.

FRIEDMAN, D; MCADAM, D. 1992. "Collective identity and activism: networks, choices, and the life of a social movement". In: MORRIS, A. D. \& MUELLER, C. MC. Frontiers in Social Movement Theory. New Haven/London: Yale University Press. pp. 156-173.

GAMSON, W. 1992. "The social psychology of collective action". In: MORRIS, A. D. \& MUELLER, C. MC. Frontiers in social movement theory. New Haven/ London: Yale University Press. pp. 53-76

GOHN, M. da G. 2002. Teorias dos movimentos sociais: paradigmas clássicos e contemporâneos. $3^{\mathrm{a}}$ ed. São Paulo: Loyola.

HABERMAS, J. 1983. The theory of communicative action - Reason and the rationalization of society. Boston: Beacon Press, vol. 1.

1987. The theory of communicative action - Lifeworld and system: a critique of functionalist reason. Boston: Beacon Press. vol. 2.

. 1990. "Ações, atos de fala, interações mediadas pela linguagem e mundo da vida”. In: __ Pensamento pós-metafísico. Rio de Janeiro: Tempo Brasileiro. pp. 65-103.

1992. "Further reflections on the public sphere". In: CALHOUN, Craig (ed.). Habermas and the public sphere. Cambridge: MIT Press. pp. $421-461$

1997. Direito e democracia: entre a facticidade e a validade. Rio de Janeiro: Tempo Brasileiro. vol. 2.

2002. A inclusão do outro: estudos de teoria política. São Paulo: Loyola. 2003. Mudança estrutural da esfera pública: investigações quanto a uma categoria da sociedade burguesa. $2^{\mathrm{a}} \mathrm{ed}$. Rio de Janeiro: Tempo Brasileiro.

HONNETH, A. 2003. Luta por reconhecimento: a gramática moral dos conflitos sociais. São Paulo: Ed. 34.

KLANDERMANS, B. 1992. "The social construction of protest and multiorganizational fields”. In: MORRIS, A. D. \& MUELLER, C. MC. Frontiers in social movement theory. New Haven/London: Yale University Press. pp. 77103.

LANÇA, I. L. "A constituição do sentido do acontecimento na experiência pública”. Trajectos, $\mathrm{n}^{\circ}$ 5, pp. 85-94.

MARTINS, M. de L. 2006. "O poder hermenêutico do acontecimento e os media". Trajectos, $\mathrm{n}^{\circ}$ 5, pp. 123-127. 
MELUCCI, A. 1996. Challenging Codes: collective action in the information age. Cambridge: Cambridge University Press.

2001. A invenção do presente: movimentos sociais nas sociedades complexas. Petrópolis: Vozes.

MENDONÇA, R. F. 2006. "Movimentos sociais e interação comunicativa: a formação da comunicação sem sujeito". Contemporânea. Revista de Comunicação e Cultura. Salvador, vol. 4, n 1 , pp. 73-98.

MOUILLAUD, M. 2002. "A crítica do acontecimento ou o fato em questão". In: _ O Jornal - da forma ao sentido. $2^{\mathrm{a}}$ ed. Brasília: Editora UnB. pp. 49-83.

MUELLER, C. 1992. "Building social movement theory". In: MORRIS, A. D. \& MUELLER, C. MC. Frontiers in Social Movement Theory. New Haven/London: Yale University Press. pp. 3-25.

NORA, P. 1988 [1972]. "O retorno do fato". In: LE GOFF, J \& NORA, P. (org). História: novos problemas. Rio de Janeiro: Francisco Alves. pp. 179-193.

PONTE, C. 2006. "Media e acontecimentos (com)sentidos". Trajectos, $\mathrm{n}^{\circ} 5$, pp. 101-104.

PRADO, M. A. M. 2002. "Da mobilidade social à constituição da identidade política: reflexões em torno dos aspectos psicossociais das ações coletivas". Psicologia em Revista. Belo Horizonte, vol. 8, n 11, pp. 59-71.

142 QUÉRÉ, L. 1982. "Des miroirs équivoques: aux origines de la communication moderne". Paris: Aubier Montaigne.

. 1995. "L'espace public comme forme et comme événement. In: JOSEPH, Osaac (org.) Prendre place. Espace public et culture dramatique. Colloque de Cerisy: Association des Amis de Pontigny-Cerisy/Éditions Recherches. pp. 93-110

2005. "Entre facto e sentido: a dualidade do acontecimento". Trajectos, $\mathrm{n}^{\circ}$ 5, pp. 59-75.

SOMERS, M E GIBSON, G. 1994. "Reclaiming the epistemological other: narrative and the social constitution of identity". In: CALHOUN, Craig (ed.) Social theory and the politics of identity. Cambridge: Cambridge University Press. pp. 37-80.

TAYLOR, C. 1997. As fontes do self. São Paulo: Loyola.

VERÓN, E. 1980. "A semiose social”. In: A produção do sentido. São Paulo: Cultrix. pp. 173-204. 


\section{TWENTY YEARS LATER: THE BRAZILIAN DEMOCRACY VIEWED FROM SÃO PAULO'S PERIPHERY}

Social movements always sought political status. This article tells the story of one of those actors, the Movement for the Defense of Favelados (MDF), which since the late 1970's operates in the eastern outskirts of the city of Sao Paulo. By telling this story of thirty years, twenty of which lived under the "new democracy", the text highlights the different forms of relationship between politics and popular sectors in the contemporary Brazil. On one side, there are some trends in direction of diluting the border that cut, during the authoritarian regime, the popular segments from the political representation. On the other side, there are new frontiers which even under a formal system based on the universality of rights, reappear today between the popular sectors and the political world.

Keywords: Social movements; Poverty; São Paulo; Democracy; Representation.

\section{MOVIMENTOS SOCIAIS COMO ACONTECIMENTOS: LINGUAGEM E ESPAÇO PÚBLICO}

\section{RICARDO FABRINO MENDONÇA}

De cunho conceitual, o presente artigo busca refletir sobre os processos de constituição e atuação de movimentos sociais com base na noção de acontecimento. A idéia é analisar a potência desestabilizadora que pode ser desencadeada por tais agências coletivas, que instauram práticas participativas fundamentais à democracia. Inicia-se essa discussão com uma sucinta apresentação do conceito de acontecimento, orientando-nos principalmente pelas idéias de Louis Quéré. Em seguida, busca-se estabelecer algumas relações entre tal conceito e os movimentos sociais, ressaltando a relevância das noções arendtianas de ação e refundação. Procura-se, então, evidenciar o caráter de acontecimento dos 
desdobramentos públicos das lutas de um movimento, com base na noção de esfera pública. Discorre-se, por fim, sobre o freqüente processo de engessamento dessa agência coletiva na burocratização de uma entidade que se quer unificada.

Palavras-chave: Acontecimento; Movimentos sociais; Esfera pública.

\section{SOCIAL MOVEMENTS AS EVENTS: LANGUAGE AND PUBLIC SPACE}

This paper makes use of the concept of "event" in order to reflect on the processes through which social movements act and constitute themselves. The idea is to analyze the displacing potential that can be engendered by these collective agencies, which give life to participative practices that are essential to democracy. The discussion begins with a brief presentation of the concept of event, focusing especially on the ideas of Louis Quéré. In the sequence, it establishes some connections between the concept of "event" and social movements, highlighting the importance in this context of Arendt's notions of "action" and "new beginning". At this point the paper evidences that the public unfolding of a social movement struggle can be thought of as an "event", if one has in mind the meaning of such concept. Finally, it discusses the recurrent process of crystallization of these collective agencies by means of their unification in a bureaucratized entity.

Keywords: Event; Social movements; Public sphere.

\section{É POSSÍVEL UMA POLÍTICA DELIBERATIVA PARA 0 TRABALHO?}

\section{LEONARDO MELLO E SILVA}

As relações trabalhistas vêm apresentando uma série de iniciativas de negociação inovadoras nos últimos anos no Brasil, seja no âmbito da concertação social, seja no âmbito 